\title{
8 Navigating power relations in a participatory music practice in a hospital
}

\author{
Karolien Dons and Helena Gaunt
}

With growing scientific evidence suggesting that music has a positive effect on people's wellbeing (Fancourt \& Finn, 2019; MacDonald, 2013; Van der Wal et al., 2018), and awareness of the need to humanise medical environments (Viney et al., 2015) and the role that the arts can play within this (Wilson et al., 2016), musicians are becoming increasingly active in the healthcare sector. More often than not, this marks an expansion in areas of professional practice for musicians. It does not, however, simply mean that their existing practices are transferred directly into healthcare contexts; rather considerable efforts have to be made to tailor-make work appropriate to the setting, often co-curating this with healthcare professionals themselves and attending to a complex and interrelating set of musical, socio-cultural, and ethical issues that lie at the heart of professionalism.

One context that deserves specific attention is that of medical hospitals, in which music's contribution to wellbeing has potential both for patients and for care professionals. Musicians who wish to expand their live music practices beyond the traditions of the concert stage and tuition studio, however, need to adapt their work in multiple ways and may feel required to develop their competences and understanding. This includes reframing the roles they play as professionals, the way they use artistic materials, and the nature of their interpersonal interactions. Across these elements, a range of established power relations are challenged. Although power relations are a fundamental component of professionalism (Empson \& Langley, 2015), they have tended to remain tacit within professional practices in music.

Power relations, understood here holistically, are both embedded systemically within the culture of particular practices (for example, in the structures and conventions of classical music performances), and an aspect of individual and collective agency (for example, professional musicians and audiences alike have choices about the ways in which they engage with and participate in performances). According to Bourdieu (1984), power relations are critical to the culture of any profession and how it operates in society. Such analysis perceives the "field" of a profession as a social space that is inherently competitive. Players take up positions informed by the "capital" they have available to play the game characterising the field. An individual's capital encompasses both social and cultural capital (these being the assets they bring with them), and the

DOI: $10.4324 / 9781003108337-8$ 
resources and rewards available to them in the field. Thus, power may clearly be considered from diverse perspectives, including the capacity to influence the behaviour of others and as a property of a system (Dunbar, 2015; McDonald, 1980).

From such a holistic perspective, power relations that musicians experience are likely to shift as they move from the conventions of the concert stage to the context of a hospital ward. These include changes in their relationships as artists to their "audiences"; changes as they collaborate with healthcare professionals; changes in their own perceptions of the power of their art form and its ability to impact or empower others; and changes in their understanding of associated criteria of quality relating to music making and professional practice. Thus, the dynamics of the hospital as a specialised, clinical, yet unpredictable environment may challenge established social and cultural structures, and the power relations within them. It must also be noted that the presence of music in a hospital may also create a shift in power for medical professionals in terms of the hierarchy of who is being cared for. This, for example, lines up with a growing agenda of selfcare in the medical world, where the importance of being cared for in order to care for others is gaining terrain (Nelson et al., 2002).

This chapter reflects on some of the opportunities and challenges of shifting power relations for musicians, through the particular lens of western classical musicians engaged in researching a participatory music practice in a hospital in the Netherlands. The chapter starts by providing some context to power relations in the field of professional music making. It continues by analysing a specific interaction taken from the musicians' hospital practice, and concludes by discussing implications for these musicians' learning and professional practice. A spectrum of power relations is addressed that pertains both to the professional system, and to the musicians' agency within it. Power, therefore, is understood to manifest through a combination of societal, cultural and (music) professional legacies, through the specifics of the healthcare situation, and through the embodied individual.

\section{Interpersonal power relations in professional music making}

\section{Power relations and the concert stage}

For western classical musicians trained in the first instance as performers, power relations are immediately evident, for example, in the concert stage setting. The social process of music making has become increasingly well understood in the last decades (Cook, 2001; Frith, 1996; Small, 1998), and for example, the nature of the dynamics constituted between "musicians" and "audiences" are a growing research field (see for example Burland \& Pitts, 2016). Furthermore, it has been demonstrated that power relations embodied within the process of music making itself, for example, in the ways music is constructed through cues from particular individuals within an ensemble, may replicate and indeed reinforce the dynamics of social hierarchies within a community (Moulin, 2004). 
Musicians, audiences, and even concert promoters take up certain positions that are clearly mediated by their cultural and social capital. Some elements of this capital are determined by the cultural and social norms of, for example, concert going: the set-up of a stage and audience; the expectations of shape and duration of performances; interactions between musicians and audience during the music making, including talking to the audience, clapping and so on; and in the social spaces around the concert auditorium, for example during intervals (Burland \& Pitts, 2016).

\section{Power in the master apprentice model of professional education}

Other elements of cultural and social capital are determined by personal standing within the music profession. For musicians themselves, a key feature that influences their enculturation into the profession is the apprenticeship model. Traditionally this has been suffused with significantly hierarchical power relations, both within the central one-to-one interactions between student and teacher (Gaunt, 2008, 2010; Persson, 1994), and within the culture of training institutions as a whole (Kingsbury, 1988; Nettl, 1995). In the last 30 years, both have become an increasing focus of research. This illuminated important factors shaping the process of finding a place within the profession, alongside the practical handing down of craft skills and musicianship that take place within professional education (Bennett \& Hannan, 2010; Perkins, 2013; Scharff, 2017). Equally, it has shown significant developments within practice that are opening apprenticeships up towards stronger collaboration and interdependence between students (emerging artists) and teachers (established artists) (Carey et al., 2013; Carey et al., 2017; Gaunt \& Westerlund, 2013; Rink, Gaunt, \& Williamon, 2017). As Perkins (2013) demonstrates, institutional hierarchies within professional apprenticeship in music interact with what students can learn, and how they do this. Consequently, students may have different experiences within the cultural hierarchies of the institution and wider music profession, and how they are able to evolve their position over time.

A central factor underpinning both apprenticeship and professional standing has been commitment to a value system premised on artistic quality. The concept of artistic quality has been challenged by some for the ways in which it is too closely connected to a particular classical canon, and to its reproduction in performance in particular ways by a relatively narrow group (Cook, 2017; Leech-Wilkinson, 2016). Critical attention has turned to a range of social issues, including equality, diversity, and inclusion, that emphasise the culturally constructed nature of concepts of "artistic quality", and ways in which historically these have tended to be upheld predominantly by a white, male group who are most highly paid in the arts (Brook et al., 2018). Analysis of artistic quality in this way has also served to reveal some of its challenges, not least in protecting individual advantages gained in terms of artistic success and professional position (Ashley, 2009), and unequal access to learning experiences (Perkins, 2013; Davies, 2004). 
Power relations in the western classical music tradition, and professional education associated with it, are clearly strongly embedded within the cultural systems, albeit often at tacit levels and partly obscured by a dominating focus on "artistic quality". This provides a significant challenge for musicians, and perhaps particularly in contexts where traditional power relations (of the stage or professional learning) are destabilised and become more fluid, as may well be the case in more hybrid spaces, including healthcare settings.

\section{Shifting constellations of power relations in hybrid settings}

Hybrid spaces may challenge power relations that are most familiar to musicians when a shift is made from the notion of a passively attending "audience" to the notion of "participants", people who are actively engaged in one form or another in the musical work. This immediately encourages the space of music making to be more co-creative. Inclusive values and aims may also become more central, making leadership in the situation and the exercise of power less about what resides in individuals and more about interpersonal navigation of a socially constructed and more distributed set of potentials (De Haan \& Kasozi, 2014; Wilson et al., 2017).

Musicians clearly then need to be adept at picking up these dynamics, and at engaging with the social and ethical aspects of the situation and their own motivation within it, perhaps particularly when working with people who are vulnerable. Alongside an artistic experience, there may be ambitions to improve participants' situation in some way. Such motivations bring up questions about zeal, the desire to do good, and how these influence the work. They need to consider how to engage appropriately and reflexively with multiple ethical parameters, and it is quite possible for such zeal to be misguided (see, for example, Baker, 2016).

In a hospital setting, musicians bring with them the capital of their musical expertise, including knowledge of repertoire, improvisatory and compositional skills, ensemble and performance practices, and also the tangible capital of their instruments, etc. They also bring elements of their "habitus", including the ways in which their mindset may allow them to adapt appropriately to the context as they find themselves confronted by a complex set of questions about the kinds of practices that may be empowering, or intrusive and unethical.

Apart from a shifting habitus for the musicians, the "audience's" role changes as well. Whereas a traditional concert stage setting involves predominantly listening and potentially validating the musician-led action on stage (O'Neill \& Sloboda, 2017), in a hospital the "audience" may decide to become more active and explicitly engaged, or indeed may not wish to engage with music being offered at all. This participative shift may also transform power structures that exist for example between patient and nurse. In devising music within these settings, musicians are thus required to extend their music-specific skills with communicative and interpersonal skills and greater awareness of the other (Smilde et al., 2014). 


\section{An essential element of musicians' practice in a hospital setting: embodied power in making music}

The embodied nature of music making foregrounds potential to access something essential within an individual person's own power (Blacking, 1973; Small, 1998), although this may or may not be immediately evident.

This is particularly interesting in a hospital setting where a musician's "audience", a patient, is likely to be physically and mentally disempowered by health issues, greater dependency on medical expertise, and the hospital's specific protocols and cultural hierarchies. This situation creates a potential for the natural embodied power within the musician's music making to ignite the patient's own embodied power in some way. On the one hand, musicians may make use of the intrinsic power of live music (DeNora, 2000) that may trigger a patient to reconnect to their own resourcefulness and sense of self. On the other hand, a musician's embodied power may be experienced in terms of "passion", beyond a specialised professional skill, as something fundamental to human integrity. Foucault describes this:

passion indicates, at a new, deeper level, that the soul and the body are in a perpetual metaphorical relation in which qualities have no need to be communicated because they are already common to both; and in which phenomena of expression are not causes, quite simply because soul and body are always each other's immediate expression.

(Foucault, 1985, p. 88)

Through such "passion" in a musician's practice comes a pure, and communicable, form of personal power that may reconnect a patient with their own personal power at some level. This equally becomes a critical element for musicians to navigate in establishing an ethical praxis in such a healthcare context.

Taken together, the extent of shifting power relations for musicians, as they move beyond the conventions of the concert stage and the cultural hierarchies of apprenticeship, emphasise the importance of exploring these dynamics further, and of considering their implications for professionalism in healthcare settings.

\section{Exploring music in a hospital ward through a holistic lens of power}

Musicians Lisa ${ }^{1}$ (flute), Paul (clarinet), and Tom (cello) are spending a week on a surgical hospital ward to make music for patients and staff. ${ }^{2}$

Assuming that being part of a music making process may provide a positive meaningful experience and contribute to wellbeing, especially during significant life events, the music practice considered here aims to foster communication and participation between patients, staff, and musicians. The musical interventions are artistically led and seen as complimentary to regular hospital care, not as therapeutic. Designated "person-centred music 
making", the musical approach includes repertoire and improvised music inspired by and/or produced with participants, for example by musically depicting someone's favourite landscape.

The musicians obtained higher degrees in classical music at Dutch conservatoires about ten years ago. Since graduation, the three have been active in innovative practices including location-based performances, creative music workshops with people with dementia, and participatory music making with refugees.

The musicians visit Mr Stevens, a patient who underwent a liver transplant. During two earlier sessions that week, he had said he was intrigued by the improvisations and had asked for a piece about the onset of spring. He got the inspiration from an acquaintance's greeting card that said: "I hope you can start to make plans for the future." A telling wish, as receiving a new liver is often experienced as starting a new life. The piece was received well and the patient had ended that visit by saying: "I feel a little tension; suddenly there are three complete strangers playing at my bedside. I get a kind of attention, and that surprises me".

That third day when Tom enters the room, he leaves his cello outside and instead takes a baton with him. Lisa follows, with flute; Paul stays outside.

Tom takes seat on Mr Stevens' left bedside, next to a nurse, who was already sitting there. "Yesterday you mentioned you like the sound of the flute", says Tom. "I'd like to invite you to conduct Lisa using this baton". "Oh!" he responds. Tom then shows how it works: he moves the baton around. Lisa plays. Tom explains: "It's like you paint music in the air".

Mr Stevens looks keen to conduct and accepts the baton. As soon as he starts to move the baton around and hears Lisa translating his movements into sound, his jaw slightly drops. The nurse is fixated on the baton, and smiles when she hears the melody follow its movements. At one point Mr Stevens stops the baton in the air, and Lisa mirrors it in her playing. "I am amazed, how fun!" he says. "In the beginning you are surprised but then you realise that you can actually influence it".

Tom asks if they could play something more. Mr Stevens responds: "Actually ... I have two options for you. We talked about Queen yesterday. But then I was thinking ... as we start to know each other a little bit ... perhaps you could improvise or play an existing piece of something that represents a bonding. I start to get used to the whole and yeah ... Is that ...? Or am I asking things that ...?"

The nurse turns her head to Mr Stevens and her face shows surprise. "Sure!" the musicians respond excitedly. Tom suggests starting with the improvisation and then moving on to Queen. He leaves to fetch his instrument and asks Paul to join them. Lisa recaps once they return: "It should be about the bonding that we have with Mr Stevens now that we are here for the third time. So I was thinking about something harmonious".

Mr Stevens adds: "Yeah, something between the three of you, but with me gradually included, that is how I feel it". 
Lisa proposes that $\mathrm{Mr}$ Stevens could also signal during the piece to the musicians that he wants to play solo, with or without baton: "You may influence it, if you want to".

The music starts statically; later warm melodies arise. Slowly the music flows towards "I Want to Break Free" by Queen. Mr Stevens is visibly impressed, applauds in the end: "Very beautiful", and compliments Paul: "You were amazing today. I had a little dip again this morning, but you managed to lift my mood".

\section{Destabilising existing power structures}

The scene breaks in multiple ways with the conventions of power in classical music as described earlier in the chapter. From the perspective of the professional musician, the personal contact with the "audience" in the situation, for example, does not resemble the rather fixed hierarchies of the concert stage. Although exchange between performer and audience on a personal level can potentially enhance the experience for both (O'Neill \& Sloboda, 2017), the verbal conversation with Mr Stevens during the "performance" is unusual for classical performance, and especially so when it also serves as a source of inspiration for co-creating music.

Rather than relocating the conventions of the stage, the musicians here sought alternative ways of making music by letting themselves be informed by the setting, particularly its people. Taking a person-centred attitude, they sought sensitively for what might be appropriate and crafted the creative process accordingly. Such attitude seems to be the way for the musicians to bring power into being and tailor it to this setting, as if the shift to a hospital context confronted the musicians with their (acquired) conventions of exerting power. One challenge for the musicians in a precarious context as a hospital, then, is being able to reinvent or transform those conventions, to shift to a mindset that allows being guided by what the situation has to offer, and most of all to develop that sensitivity for appropriateness.

Breaking with many conventions of classical music performance and its professional practice, the example also reveals that the musicians' shift in approaches tangibly affect the one-person audience. The tension that $\mathrm{Mr}$ Stevens feels when three strangers are at his bedside indicates how unusual it is for him, and illustrates how such experience clashes with what classical audiences are typically enculturated to expect.

From the perspective of the hospital, where patients often feel disempowered, Mr Stevens' pro-active and embodied engagement is striking. His "being intrigued" reveals an attraction for the musical improvisations, which is perhaps not found so easily in the reproduction of existing repertoire. With uncertainty surrounding Mr Stevens' recovery, his mention of making plans for the future suggests that the musical approach has a part to play in "affording" (DeNora, 2000) Mr Stevens to strengthen his agency and to imagine a future place for himself. The specific musical approaches, including improvisation, 
which experiment with interpersonal power, become central to Mr Stevens' empowerment.

In contrast to Mr Stevens, the nurse's contribution in the situation remains relatively limited. Although the practice researched in this study intends to involve staff in the music making situation as other examples testify (see for example Smilde et al., 2019), her role here is not directly musical, but it nevertheless stands in contrast to the caring and particular "gatekeeping" responsibilities she usually holds in the room. In this sense, the music making can begin to transform existing power relations for her too in the hospital where protocols and hierarchies normally are strict.

\section{Balancing the potential and challenges of musical freedom and constraint}

The situation in Mr Stevens' room reveals that destabilising familiar power structures enables freedom and musical experiment through spontaneous creation of new music, and the adoption of Mr Stevens as co-creator. It requires the musicians to let go some of their control over the musical piece, which for a classical musician is likely to be hugely invested in the stability of the score and faithful attention to it. As much as this can be liberating and empowering, it also entails challenges.

When Mr Stevens expresses "a little tension" and getting "attention", and how this surprises him, his response may indicate positive surprise. Equally, it may indicate boundaries being stretched inappropriately - the evident discomfort can go in either direction. Although his attraction to the music and sense of empowerment point to the great potential of the situation, it is also possible that he starts to feel overpowered, and to a point that is almost too much to handle. The dynamics of the situation are delicate and reveal a critical challenge for the musicians to sense the tipping point of what is possible and positive in terms of each person's participation.

As much as the freedom in this music making is challenging, restricting that freedom is equally risky. If we consider the introduction of the baton improvisation, it can be understood from different perspectives: potentially overpowering for Mr Stevens, or alternatively providing him with some control and musical agency. When Tom took a seat next to Mr Stevens, Tom's actions appear to have had the intention of reducing the musical capital in the room, in order to create a greater sense of safety, prevent the "tension" that Mr Stevens had expressed in an earlier meeting, and enable him to be a co-creative participant. Nevertheless, the calculating actions of leaving the cello and Paul behind also seem pre-scripted, instantly restricting the palette of musical possibilities in the situation. As such, Tom's actions could be experienced as directive and not person-centred at all. In an interview after the visit, Tom elaborated on this moment of introducing the baton:

Gradually during the week and on that day we [musicians] decided how to do it. We had a clear image of someone taking back control, we thought it was 
nice to, sort of, elevate that musically-allegorically with a baton. In fact it was instantly clear that he took control anyway ... Perhaps without noticing, but he was already steering our pieces.

Tom reveals that the musicians intended to support Mr Stevens to take musical control through the directions they gave. Their pre-scripted actions were inspired by their interpretations of Mr Stevens' behaviour in previous encounters. The active shaping of power demonstrated by the musicians when they entered the room, therefore, was a tailor-made and patient-inspired, yet strongly musicianled action. A person-centred attitude may indeed have helped the musicians to respond to the situation and create the practice in vivo. Nevertheless, there were different levels at which they shaped the power relations in the situation, and these included tacit ways that were not necessarily noticed by others present. From an ethical point of view, it therefore seems critical for the musicians to understand these possible ways of shaping power relations within the process of co-creative decision-making, and to be aware of appropriate ways to make these transparent to the different participants in the situation.

\section{Blending authorial and collaborative strategies in the process of creating the musical practice}

From a classical music performance perspective, attending to the power relations in a person-centred way seems relatively new. As the musicians enter the room and hand over the baton to Mr Stevens, their initial actions suggest a strong authorial intention, while at the same time explicitly letting go of their musical control. This brings insecurity for their artistic voices, and invites greater shared leadership to emerge in the music making. The co-existence of such authorial and collaborative strategies to help steer through the power relations appears throughout the rest of the visit, to the point where it is hard to distinguish between them. This starts to indicate that the person-centred attitude entails not only attention to the other, but also inwardly and reflexively to the musicians themselves.

The baton improvisation puts Mr Stevens visibly in charge of the interaction. Lisa, by producing the sound, also asserts her own authorial power as she responds to create the music. Although the second piece emerges in a less pre-scripted way, and is less musician-directed, ownership is equally diffuse as it is in the first piece. This time Mr Stevens initiates a negotiation about the musical plan prior to playing. Later on, Lisa invites Mr Stevens to keep on influencing the music through hand movements, adding "if you want to", thereby confirming his authority and self-determination as the fourth musician.

The fluidity and elusiveness of who is in charge of both pieces, and with that letting go of musical safety, may inevitably raise questions for the musicians about delivering quality in this context. On what basis do they understand "musical quality" in this situation? What seems to happen is that in letting go of the more traditional structures of power in classical music performance, the musicians are forced to return to something fundamental in their musicianship. 
Perhaps this is what we have earlier recognised in Foucault's "passion", which then inevitably connects strongly to artistic values and identity. From this perspective it becomes evident that improvisation is useful here, not only because its fluid nature aligns well with the situation's unpredictable dynamics, but also because it is an important tool for musicians to express their sense of self as well as that of others at a profound level (Smilde, 2016). Adopting improvisation as one of the practice's key components explicitly embraces fluidity and unpredictability, and thus breaks with some central aspects of a classical music performance culture. But more than this, the process of appealing to persons (rather than to a written score) fosters a quite different creative concept for classically trained musicians.

\section{Discussion and implications for professionalising musicians}

The holistic reading of power relations in a particular hybrid setting of a music practice in a hospital presented in this chapter has highlighted the complexity and ethical dimensions of these dynamics, and the degree to which they challenge existing conceptions of classical music performance, what is involved in professional musicianship and indeed professionalism in music. This suggests that for musicians developing such practices in healthcare settings, there is an important need for critical awareness and reflection on their professional values, attitudes, and approaches to navigating the power relations that suffuse several key aspects of the practices. The professionalism of those devising this kind of work seems to have particular points of focus on:

- Creative ways of engaging people's artistry;

- Ethical competences, including (tacit) reading and responding appropriately to complex situations where dynamics of power may be highly charged and for some people quite unfamiliar;

- The opportunities and challenges of moving away from the safety of a musical score and letting go of performance conventions.

In this sense the hospital situation for musical practice indicates the value of considering it as a "learning culture" of sorts, where all those involved are engaged in forms of learning in vivo through their interactions. Understood in this way, the practice may be understood to be quite different as a site of performance compared with a concert stage, which tends to have the culture of a service expertly delivered in one direction, from the musicians to the audience. Understood as a learning culture, the work of musicians in a hospital, which they may initially perceive in terms of another "site of performance", becomes much more clearly highlighted as a site of social and collaborative practice, and one that encompasses:

not simply the human mind but the living human being in continuous interaction with its environment. 


\section{Karolien Dons and Helena Gaunt}

This perspective of music making as a learning culture may in itself be a valuable conceptual frame for musicians as they reflect on their professional practices overall, and expand their professionalism to meet the demands of emerging professional possibilities. It may also provide a stimulus for further research in the field of music in healthcare settings.

\section{Notes}

1 All names in this chapter are pseudonyms.

2 The vignette depicts a situation that took place within Meaningful Music in Healthcare (MiMiC), a collaboration between the research group Lifelong Learning in Music of the Prince Clause Conservatoire (Hanze University of Applied Sciences Groningen, The Netherlands), musicians collective Foundation Mimic Music and the department of surgery of the University Medical Center Groningen.. More on www.lifelonglearninginmusic.org.

\section{References}

Ashley, R. (2009). Musical improvisation. In S. Hallam, I. Cross \& M. Thaut (Eds.), The Oxford Handbook of Music Psychology (pp. 413-420). Oxford University Press.

Baker, G. (2016). Citizens or subjects?: El Sistema in critical perspective. In D. J. Elliott, M. Silverman \& W. D. Bowman (Eds.), Artistic Citizenship: Artistry, Social Responsibility, and Ethical Praxis (pp. 313-338). Oxford University Press.

Bennett, D. \& Hannan, M. (2010). Inside, Outside, Downside Up: Conservatoire Training and Musicians' Work. Black Swan Press.

Blacking, J. (1973). How Musical Is Man? University of Washington Press.

Bourdieu, P. F. (1984). Distinction: A Social Critique of the Judgement of Taste. Translated by Robert Nice. Routledge \& Kegan Paul.

Brook, O., O’Brien, D. \& Taylor, M. (2018). Panic! Social Class, Taste ad Inequalities in the Creative Industries. Barbican.

Burland, K. \& Pitts, S. (2016). Coughing and Clapping: Investigating Audience Experience. Routledge.

Carey, G., Bridgstock, R., Taylor, P. McWilliam, E. \& Grant, C. (2013). Characterising one-to-one conservatoire teaching: Some implications of a quantitative analysis. Music Education Research, 15, 357-368. doi:10.1080/14613808.2013.824954

Carey, G., Harrison, S. D. \& Dwyer, R. (2017). Encouraging reflective practice in conservatoire students: A pathway to autonomous learning? Music Education Research, 19(1), 99-110. doi:10.1080/14613808.2016.1238060

Cook, N. (2001). Between process and product: Music and/as performance. Music Theory Online, 7(2), https://openmusiclibrary.org/article/85042/

Cook, N. (2017). Music as Creative Practice. Studies in Musical Performance as Creative Practice. Edited by John Rink. Oxford University Press.

Davies, A. (2004). Preparing professional performers: Music students' perceptions and experience of the learning process at Birmingham conservatoire. International Journal of Qualitative Studies in Education, 17(6), 803-821. doi:10.1080/0951839042000256466

De Haan, E. \& Kasozi, A. (2014). The Leadership Shadow: How to Recognize and Avoid Derailment, Hubris and Overdrive. Kogan Page.

DeNora, T. (2000). Music in Everyday Life. Cambridge University Press. 
Dunbar, N. E. (2015). A review of theoretical approaches to interpersonal power. The Review of Communication, 15(1), 1-18. doi:10.1080/15358593.2015.1016310

Empson, L. \& Langley, A. (2015). Leadership and professionals: Multiple manifestations of influence in professional service firms. In L. Empson, D. Muzio, J. Broschak \& B. Hinings (Eds.), The Oxford Handbook of Professional Service Firms (pp. 163-188). Oxford University Press.

Fancourt, D. \& Finn, S. (2019). What Is the Evidence on the Role of the Arts in Improving Health and Well-Being? A Scoping Review. Health Evidence Network (HEN) synthesis report 67. WHO Regional Office for Europe.

Foucault, M. (1985). Madness and Civilization: A History of Insanity in the Age of Reason. Tavistock.

Frith, S. (1996). Performing Rites: On the Value of Popular Music. Harvard University Press.

Gaunt, H. (2008). One-to-one tuition in a conservatoire: The perceptions of instrumental and vocal teachers. Psychology of Music, 36(2), 215-245. doi: $10.1177 / 0305735607080827$

Gaunt, H. (2010). One-to-one tuition in a conservatoire: The perceptions of instrumental and vocal students. Psychology of Music, 38(2), 178-208. doi:10.1177/0305735609339467

Gaunt, H. \& Westerlund, H. (2013). Collaborative Learning in Higher Music Education. Ashgate.

James, D. \& Biesta, G. (2007). Improving Learning Cultures in Further Education. Routledge.

Kingsbury, H. (1988). Music, Talent and Performance: A Conservatory Cultural System. Temple University Press.

Leech-Wilkinson, D. (2016). Classical music as enforced Utopia. Arts and Humanities in Higher Education, 15(3-4), 325-336. doi:10.1177/1474022216647706

MacDonald, R. A. R. (2013). Music, health, and well-being: A review. Int J Qualitative Stud Health Well-being, 8(1). doi:10.3402/qhw.v8i0.20635.

McDonald, G. W. (1980). Family power: The assessment of a decade of theory and research, 1970-1979. Journal of Marriage and the Family, 42, 841-854.

Moulin, J. F. (2004). Cueing up: Situating power on the Tahitian stage. Yearbook for Traditional Music (pp. 109-127). International Council for Traditional Music.

Nelson, E. C., Batalden, P. B., Huber, T. P., Mohr, J. J., Godfrey, M. M., Headrick, L. A. \& Wasson, J. H. (2002). Microsystems in health care: Part 1. Learning from highperforming front-line clinical units. Joint Commission Journal on Quality Improvement, 28, 472-493. doi:10.1016/S1070-3241(02)28051-7

Nettl, B. (1995). Heartland Excursions: Ethnomusicological Reflections on Schools of Music (Music in American Life). University of Illinois Press.

O'Neill, S. \& Sloboda, J. (2017). Responding to performers: Listeners and audiences. In J. Rink, H. Gaunt \& A. Williamon (Eds.), Musicians in the Making: Pathways to Creative Performance (pp. 322-340). Oxford University Press.

Perkins, R. (2013). Hierarchies and learning in the conservatoire: Exploring what students learn through the lens of Bourdieu. Research Studies in Music Education, 35(2), $197-$ 212. doi:10.1177/1321103X13508060

Persson, R. S. (1994). Concert musicians as teachers: On good intentions coming short. European Journal for High Ability, 5(1), 79-91. doi:10.1080/0937445940050108

Rink, J., Gaunt, H. \& Williamon, A. (2017). Musicians in the making: Pathways to creative performance. In J. Rink (Ed.), Studies in Musical Performance as Creative Practice. Oxford University Press. 


\section{Karolien Dons and Helena Gaunt}

Scharff, C. (2017). Gender, Subjectivity and Cultural Work: Classical Music Profession. Routledge.

Small, C. (1998). Musicking: The Meanings of Performing and Listening. Wesleyan University Press.

Smilde, R. (2016). Biography, identity, improvisation, sound: Intersections of personal and social identity through improvisation. Arts \& Humanities in Higher Education, 15(3-4): 308-324. doi:10.1177/1474022216647374

Smilde, R., Page, K. \& Alheit, P. (2014). While the Music Lasts-On Music and Dementia. Eburon.

Smilde, R., Heineman, E., de Wit, K., Dons, K. \& Alheit, P. (2019). If Music be the Food of Love, Play On. Meaningful Music in Health Care. Eburon.

Van der Wal-Huisman, H., Dons, K., Smilde, R., Heineman, E. \& Van Leeuwen, B. (2018). The effect of music on postoperative recovery in older patients: A systematic review. Journal of Geriatric Oncology, 9, 550-559. doi:10.1016/j.jgo.2018.03.010

Viney, W., Callard, F. \& Woods, A. (2015). Critical medical humanities: Embracing entanglement, taking risks. Medical Humanities, 41, 2-7. doi:10.1136/ medhum-2015-010692

Wilson, C., Bungay, H., Munn-Giddings, C. \& Boyce, M. (2016). Healthcare professionals' perceptions of the value and impact of the arts in healthcare settings: A critical review of the literature. International Journal of Nursing Studies. 56, 90-101. doi:10.1016/j. ijnurstu.2015.11.003

Wilson, N., Gross, J. \& Bull, A. (2017). Towards Cultural Democracy: Promoting Cultural Capabilities for Everyone. King's College. 